\title{
Influence of Nanographite on Dry Sliding Wear Behaviour of Novel Encapsulated Squeeze Cast Al-Cu-Mg Metal Matrix Composite Using Artificial Neural Network
}

\author{
L. Natrayan $\left(\mathbb{D},{ }^{1}\right.$ M. Ravichandran $\mathbb{D}^{2},{ }^{2}$ Dhinakaran Veeman $\mathbb{D},{ }^{3}$ P. Sureshkumar $\mathbb{D},{ }^{4}$ \\ T. Jagadeesha, ${ }^{5}$ and Wubishet Degife Mammo ${ }^{6}$ \\ ${ }^{1}$ Department of Mechanical Engineering, Saveetha School of Engineering, SIMATS, Chennai, 602105 Tamil Nadu, India \\ ${ }^{2}$ Department of Mechanical Engineering, K.Ramakrishnan College of Engineering, Samayapuram, 621112 Tamil Nadu, India \\ ${ }^{3}$ Centre for Additive Manufacturing and Computational Mechanics, Chennai Institute of Technology, Chennai, \\ 600069 Tamil Nadu, India \\ ${ }^{4}$ Department of Mechanical Engineering, Ramco Institute of Technology, Virudhunagar, 626125 Tamil Nadu, India \\ ${ }^{5}$ Department of Mechanical Engineering, National Institute of Technology, Calicut, 673601 Kerala, India \\ ${ }^{6}$ Mechanical Engineering Department, Wollo University, Kombolcha Institute of Technology, Kombolcha, South Wollo, \\ 208 Amhara, Ethiopia
}

Correspondence should be addressed to L. Natrayan; natrayanphd@gmail.com,

Dhinakaran Veeman; dhinakaranv@citchennai.net, and Wubishet Degife Mammo; wubishetdegife7@gmail.com

Received 8 September 2021; Revised 20 October 2021; Accepted 1 November 2021; Published 19 November 2021

Academic Editor: Lakshmipathy R

Copyright (c) 2021 L. Natrayan et al. This is an open access article distributed under the Creative Commons Attribution License, which permits unrestricted use, distribution, and reproduction in any medium, provided the original work is properly cited.

This paper investigates the dry sliding wear behaviour of squeeze cast $\mathrm{Al}-\mathrm{Cu}-\mathrm{Mg}$ reinforced with nanographite metal matrix composites. The experimental study employed the Taguchi method. The Taguchi method plays a significant role in analyzing aluminium matrix composite sliding tribological behaviour. Specifically, this method was found to be efficient, systematic, and simple relative to the optimization of wear and friction test parameters such as load $(10,20$, and 30$)$, velocity $(0.75,1.5$, and $2.25 \mathrm{~m} / \mathrm{s})$, and nanographite $(1,3$, and $5 \mathrm{wt} \%)$. The optimization and results were compared with the artificial neural network. An orthogonal array L27 was employed for the experimental design. Analysis of variance was carried out to understand the impact of individual factors and interactions on the specific wear rate and the coefficient of friction. The wear mechanism, surface morphologies, and composition of the composites have been investigated using scanning electron microscopy with energy-dispersive X-ray spectroscopy. Results indicated that wt\% addition of nanographite and increase of sliding speed led to a decrease in the coefficient of friction and wear rate of tested composites. Furthermore, individual parameter interactions revealed a smaller impact. The interactions involved wt\% of nano-Gr and sliding speed, sliding speed and normal load, and wt $\%$ of nano-Gr and normal load. This inference was informed by the similarity between the results obtained ANN, ANOVA, and the experimental data.

\section{Introduction}

In modern society, there is an increasing demand for new hybrid composites. Particularly, the demand emphasizes lightweight alloys. Most previous studies indicate that this demand trend comes from construction price decrease, mass construction reduction, and working life increase [1]. One of the examples of the demand concerns the use of aluminium and its associated alloys to substitute steel and materials similar to the latter. Notably, the demand for aluminium alloys has arisen from the affirmation that the alloys exhibit good mechanical properties [2, 3]. However, some studies caution that the alloys have poor tribological characteristics. Imperative to highlight is that tribological characteristics concern wear, lubrication, and friction of interacting surfaces, especially those found to be in relative motion [4]. 
The demerit of poor tribological characteristics of aluminium alloy, although lightweight materials, has paved the way for improvements. Related composite materials have been developed in a quest to steer improvements to the material tribological characteristics [3, 4]. An example of composite materials is a case of Al-Si alloy (A356). Some scholarly investigations have also analyzed the information obtained from referent literature reviews concerning composite material exploitation [5]. For these studies, findings avow that the addition of specific reinforcements tends to improve the aluminium alloy mechanical characteristics [6]. Some of the reinforcements that have gained application in the quest to improve the aluminium alloy mechanical characteristics include $\mathrm{Al}_{2} \mathrm{O}_{3}$ and $\mathrm{SiC}$.

Imperatively adding some volume amounts or masses of reinforcements to the aluminium alloys has led to a problem concerning the composite material mechanical treatment [7]. To solve this problem, nanographite has been proposed as an ideal material that could be added at a certain quantity. For investigations that have examined the latter process, most of the results concur that the resultant composite's tribological characteristics, due to nanographite addition, tend to improve [6,7]. When two or more reinforcements are used to develop composite materials, the latter is translated into hybrid composite materials [8]. Some of the areas that have received attention relative to aluminium alloys and the hybrid composite tribological behaviour include electronic industry, aircraft, and automobiles. Currently, composite material production usage and annual growth lie at $6 \%$, with the aluminium base on focus [9]. Different methods have been applied to steer the development of hybrid aluminium matrix composites (HMMC), which are mostly achieved by combining soft graphite particles and hard ceramic. Some of these methods include full factorial and response surface, analysis of covariance (ANOVA), and Taguchi [10-14]. The role of these methods has been to provide information regarding the possible impact of different parameters, assuming hierarchical rank orders. The methods mentioned above have tested the specific parameters: the impact of graphite or reinforcement weight percentage, the sliding speed and distance, and the normal load on hybrid AMCs' friction and wear properties [15, 16]. Most of the researchers have employed the ANOVA method and an orthogonal array. For these studies, findings suggest that in dry sliding conditions, the use of graphite particles proves effective in decreasing friction and increasing the wear resistance of AMCs [17].

For hybrid $\mathrm{Al} / \mathrm{SiC} / \mathrm{Gr}$ composite materials, the tribological behaviour has been investigated. For these investigations, graphite content with 2.5 and $8 \mathrm{wt} \%$ and $\mathrm{SiC}$ content with $10 \mathrm{wt} \%$ have been considered. The base used has been aluminium alloy Al 2024, with the semisolid powder densification method aiding in making composites [18]. Also, the metal matrix Al-Si7Mg composite's tribological behaviour has been investigated [16-19]. The reinforcement for the latter investigation has been achieved via $10 \% \mathrm{SiC}$ and graphite particles without lubrication. With full factorial design gaining application, the central objective has been to unearth the impact of reinforcement content in terms of sliding distance, sliding speed, load, and percentage on the wear of $\mathrm{Al}$ alloy/ $\mathrm{SiC} /$ graphite composite materials, $\mathrm{Al}$ alloys/SiC, and $\mathrm{Al}$ alloy/graphite. In the finding, these experimental studies suggest that hybrid composite material exhibits the best characteristics.

Imperative to note is that the decision to incorporate approaches such as factorial and surface response and Taguchi, which constitute the design of experiment (DOE) concepts, has been informed by the need to gain insights into the impact of different parameters, with the results obtained in terms of hierarchical rank order [20]. The techniques have also proved important by providing room for establishing correlation terms and the analysis of the parameters' combined effects [21]. Some investigations have focused on graphite $(\mathrm{Gr})$ and silicon carbide $(\mathrm{SiC})$ as reinforcements to understand the different behaviour of hybrid composites. For these studies, aluminium base Al 2219 has been used. The liquid metallurgy synthesis approach has been employed during the making of the hybrid composites [22]. With the Taguchi method embraced, a major focus has been to analyze the impact of reinforcement content in wt $\%$, sliding distance, sliding speed, and normal load [20, 21]. For the latter investigations, findings indicate that in $\mathrm{wt} \%$, where reinforcement is done via the increase of graphite content, there is likely to be an increase in the hybrid composites' resistance to wear.

Imperatively, the aluminium bases used in most previous studies have been $\mathrm{Al} 2219$ and $\mathrm{Al} 2024$ [22]. Also, the majority of the studies have focused on hybrid AMCs or aluminium hybrid composites under dry sliding conditions [20-22]. It is also worth noting that from the critical review of the current literature, the majority of the investigations have used techniques such as Taguchi and ANOVA to establish hierarchical rank orders of test parameters independently [23]. Some of the test parameters considered include the weight percentage of graphite or reinforcements, the sliding speed and distance, and the normal load. As such, most of the experiments have not focused on the combined impact that the parameters pose on wear and friction. Therefore, the main aim of the current study is to find out the tribological behaviour of aluminium hybrid composites with $\mathrm{Al}-\mathrm{Cu}-\mathrm{Mg}$ reinforced nanographite. It is also imperative to highlight that the investigation employs the Taguchi method.

\section{Experimental Details}

2.1. Materials. In this study, $\mathrm{Al}-\mathrm{Cu}-\mathrm{Mg}$ is used as the base for metal matrix composite. The squeeze casting process is used to fabricate the composite specimens. Figure 1 shows the squeeze casting machine. The materials used in squeeze casting include nanographite with each stretching to $10 \mathrm{~nm}$. The experiment also involved overheating and melting the matrix alloy to ensure that it was clean of slag. The overheating and melting procedure extended to $650^{\circ} \mathrm{C}$. This process preceded the compocasting procedure. Homogenous mixing was done with nanographite powders. With the process conducted in the solid state, the preheating stage that followed extended to $150^{\circ} \mathrm{C}$. The procedure followed involved the 

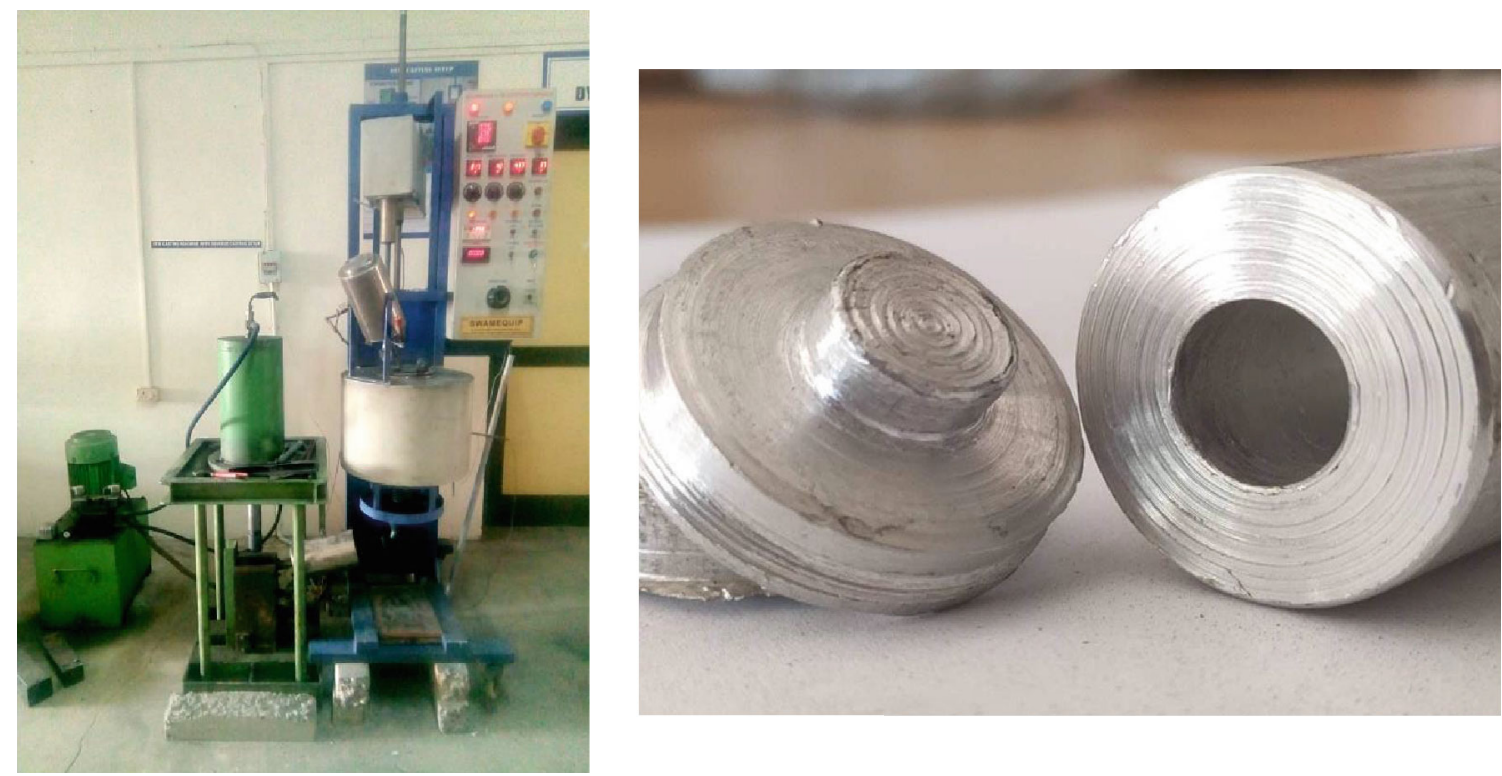

FIgURE 1: Squeeze casting setup and novel encapsulated metal cap.

cooling of the alloy matrix, which was brought down to a range of $597^{\circ} \mathrm{C}-603^{\circ} \mathrm{C}$. Imperative to note is that the latter temperature range was maintained for 10 minutes. With a semisolid melt obtained, a plate mixer was introduced, followed by a five-minute isothermal stirring procedure. This procedure was set at $500 \mathrm{rpm}$. Also, a squeeze casting procedure was conducted. The procedure lasted 15 seconds, and pressure was set at $90 \mathrm{MPa}$.

The nanographite particle was filled in the metal cap and melt in a squeeze casting furnace. The novel encapsulated metal cap is shown in Figure 1. The motivation to increase the temperature was informed by the need to promote the infiltration process with the secondary phase particle addition making the semisolid matrix increase in velocity. The temperature was also increased to $610^{\circ} \mathrm{C}$ in response to the increasing particle amount.

Figure 2 shows the Pin on Disc wear testing machine. On completing the infiltration procedure, the moving process that followed was in two stages. The initial stage lasted two minutes and was aimed at stabilizing the moving process. At this point, $1000 \mathrm{rpm}$ was the rotation speed of the plate mixer. Similarly, this initial stage was marked by a restoration of temperature back to $600^{\circ} \mathrm{C}$. The stage that followed was conducted in five minutes. Particularly, $1500 \mathrm{rpm}$ was the rotation speed of the plate mixer, taking place in an isothermal context.

To ensure that the semisolid melts were cast successfully, the experiment employed a mold. This mold had been preheated to $500^{\circ} \mathrm{C}$. Later, a special tool was set at $570^{\circ} \mathrm{C}$ and used to hot press the obtained castings. The hot pressing also involved a $100 \mathrm{MPa}$ pressure. Particularly, commercial T6 heat treatment was the platform to which the experiment's specimens were subjected. Wear specimens are shown in Figure 3. Parameters of commercial T6 included artificial ageing and water quenching for $6 \mathrm{~h}$ and at $160^{\circ} \mathrm{C}$, and the solution is heat-treated for $4 \mathrm{hr}$ and at $540^{\circ} \mathrm{C}$. Table 1 illus-

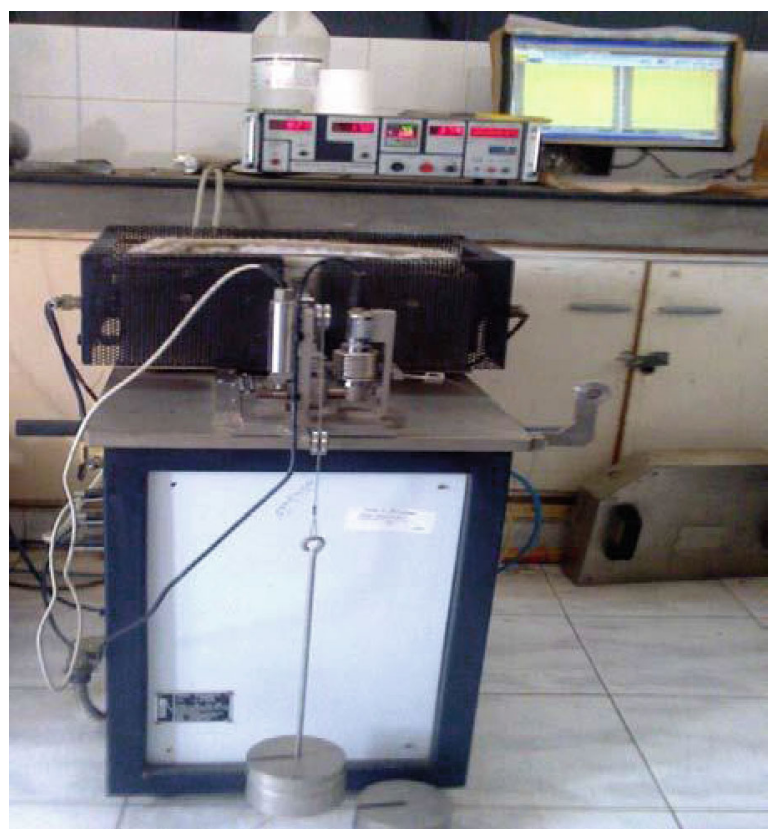

Figure 2: Pin on Disc wear testing machine.

trates the chemical properties or composition of the $\mathrm{Al}$ $\mathrm{Cu}-\mathrm{Mg}$ used.

2.2. The Case of Wear and Friction Tests. The wear and friction tests focused on material tribological behaviour. The ASTM G77 standard governed the investigation whereby block-on-disc contact geometry dominated the procedure. Also, TPD 93, a computer-aided tribometer, formed a platform for testing the tribological behaviour. As the experiment proceeded, the thickness of discs and blocks was $6.35 \mathrm{~mm}$, which marked the initial contact. $\mathrm{Ra}=0.2 \mu \mathrm{m}$ 


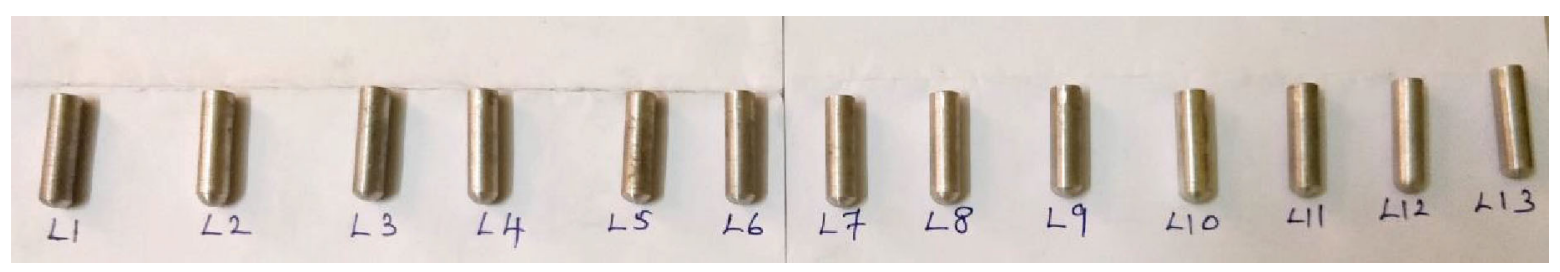

Figure 3: Wear samples.

TABLe 1: Chemical composition of Al-Cu-Mg.

\begin{tabular}{lccccccccc}
\hline Element & $\mathrm{Al}$ & $\mathrm{Mg}$ & $\mathrm{Si}$ & $\mathrm{Fe}$ & $\mathrm{Cu}$ & $\mathrm{Mn}$ & $\mathrm{Cr}$ & $\mathrm{Zn}$ & $\mathrm{Ti}$ \\
\hline Weight \% & 97.81 & 0.95 & 0.54 & 0.22 & 0.17 & 0.13 & 0.09 & 0.08 & 0.01 \\
\hline
\end{tabular}

TABLE 2: Dry sliding wear parameters and their levels.

\begin{tabular}{lccc}
\hline Controllable factors & Level 1 & Level 2 & Level 3 \\
\hline Load $(\mathrm{N})$ & 10 & 20 & 30 \\
Velocity $(\mathrm{m} / \mathrm{s})$ & 0.75 & 1.5 & 2.25 \\
Nanographite $\mathrm{wt} \%$ & 1 & 3 & 5 \\
\hline
\end{tabular}

constituted the surface roughness of the tested composite materials, which formed the blocks.

On the other hand, $\mathrm{Ra}=0.3 \mu \mathrm{m}$ reflected the disc's surface roughness. Also, $90 \mathrm{MnCrV} 8$ steel was selected for the disc. The hardness of this disc stretched from 62 HRC to 64 HRC. The lubricant employed in this study involved ISO VG 46 hydraulic oil. The selection of this form of oil was informed by its recommended industrial application in situations involving high-pressure mechanical systems such as roller bearings, chain gears, and gearboxes. The submergence of the selected discs (into the oil) extended to $3 \mathrm{~mm}$.

As the friction and wear tests progressed, the lubricated conditions involved five major sliding speeds. These speeds included $0.75,1.5$, and $2.25 \mathrm{~m} / \mathrm{s}$. Also, the normal loads embraced included 10, 20, and $30 \mathrm{~N}$. Regarding the sliding distances, the study focused on nanographite such as 1,3 , and $5 \mathrm{wt} \%$ for the speeds and loads above, respectively. The choice of these ranges of normal load and sliding speed arose from their wide practical applications at roller bearings, chain gears, and gearboxes. The tribological behaviour of the selected materials have measured wear tracks, and the coefficient of friction was read continuously at the end of the respective tests. Dry sliding wear parameters and their levels are exposed in Table 2. Imperative to note is that each test or experiment was repeated thrice.

2.3. Experimental Design: Taguchi Method. The Taguchi method is employed in controlled settings, and its purpose is to analyze the impact that process variables are likely to have on other specific variables. The specific variables under investigation are usually unknown functions of process variables. After implementing the Taguchi method, the findings are used to inform industrial designs of improved and quality systems [24]. Practically, the Taguchi method has been applied by many previous researchers to understand aluminium metal matrix composites' sliding wear behaviour. Hence, the Taguchi method supports the creation of standard orthogonal arrays responsible for accommodating the influence of different variables on target values. To study the impact of parameters on the independent variables, ANOVA was used to analyze the results and make the Taguchi method meaningful [25].

When experimental results are established after applying the Taguchi method, they are usually converted into signalto-noise $(\mathrm{S} / \mathrm{N})$ ratios. The Taguchi method incorporates statistical analyses of variance to predict optimal combinations that could be used based on the test parameters. As avowed by other studies, the latter procedure seeks to define or establish parameters that are deemed statistically significant and worth considering $[26,27]$.

With Taguchi giving the "smaller the better" characteristics relative to the wear rate ratio $(\mathrm{S} / \mathrm{N})$,

$$
\mathrm{S} / \mathrm{N}=-10 \log \left(\frac{1}{n} \sum_{i=1}^{n} \frac{1}{y^{2}}\right) \text { (larger is better). }
$$

In equation (1), $n$ represent the number of observations made while $y_{1}, y_{2}, \cdots, y_{n}$ reflect sliding wear responses. Table 3 summarizes the average of characteristics associated with various levels of experimental factors.

\section{Results and Discussion}

This study sought to establish the most significant parameters and parameter combinations that are likely to exhibit the greatest impact on the coefficient of friction and the wear rate. By establishing these parameters, the experiment would then give an insight into how their values could be reduced to the minimum. The orthogonal array governed the tests to connect the impacts of nanographite wt\%, sliding speed $(S)$, and load $(L)$. These parameters were also used due to their capacity to define the composite tribological behaviour and important influence on this process. Tables 4 and 5 show the signal-to-noise ratio for wear rate and coefficient of friction response.

3.1. ANOVA and the Resultant Impact of Factors or Parameters. The variance analysis (ANOVA) aided in analyzing the experimental results. ANOVA sought to give an insight into percentage factors that tend to influence the friction coefficient and wear intensity individually. Tables 6 and 7 highlight the ANOVA results. At $P<0.05$, the results 
TABLE 3: Experimental design using L27 $\left(3^{3}\right)$ orthogonal array.

\begin{tabular}{|c|c|c|c|c|c|c|c|c|c|}
\hline $\begin{array}{l}\text { Sample } \\
\text { Id }\end{array}$ & $\begin{array}{l}\text { Load } \\
(\mathrm{N})\end{array}$ & $\begin{array}{l}\text { Velocity } \\
(\mathrm{m} / \mathrm{s})\end{array}$ & $\begin{array}{c}\text { Nanographite } \\
\text { wt } \%\end{array}$ & $\begin{array}{c}\text { Wear rate } \\
\times 10^{-3}\left(\mathrm{~mm}^{3} / \mathrm{m}\right)\end{array}$ & $\mathrm{COF}$ & $\begin{array}{l}\mathrm{S} / \mathrm{N} \text { ratio for wear } \\
\text { rate }\end{array}$ & $\begin{array}{l}\mathrm{S} / \mathrm{N} \text { ratio for } \\
\mathrm{COF}\end{array}$ & $\begin{array}{l}\text { ANN wear } \\
\text { rate }\end{array}$ & $\begin{array}{l}\text { ANN } \\
\text { COF }\end{array}$ \\
\hline S1 & 10 & 0.75 & 1 & 0.323 & 0.4146 & 9.8159 & 7.6474 & 0.3230 & 0.4254 \\
\hline S2 & 10 & 0.75 & 3 & 0.3186 & 0.3162 & 9.9351 & 10.001 & 0.3200 & 0.3148 \\
\hline S3 & 10 & 0.75 & 5 & 0.3611 & 0.3651 & 8.8475 & 8.7518 & 0.3579 & 0.3598 \\
\hline S4 & 10 & 1.5 & 1 & 0.331 & 0.5477 & 9.6034 & 5.2291 & 0.3310 & 0.5582 \\
\hline S5 & 10 & 1.5 & 3 & 0.4166 & 0.3126 & 7.6056 & 10.1 & 0.4168 & 0.2980 \\
\hline S6 & 10 & 1.5 & 5 & 0.438 & 0.4955 & 7.1705 & 6.0991 & 0.4380 & 0.5019 \\
\hline S7 & 10 & 2.25 & 1 & 0.3568 & 0.5539 & 8.9515 & 5.1314 & 0.3568 & 0.5599 \\
\hline S8 & 10 & 2.25 & 3 & 0.3959 & 0.5168 & 8.0483 & 5.7335 & 0.3959 & 0.5347 \\
\hline S9 & 10 & 2.25 & 5 & 0.451 & 0.6258 & 6.9165 & 4.0713 & 0.4510 & 0.6460 \\
\hline S10 & 20 & 0.75 & 1 & 0.321 & 0.3256 & 9.8699 & 9.746 & 0.3214 & 0.3441 \\
\hline S11 & 20 & 0.75 & 3 & 0.2766 & 0.3569 & 11.163 & 8.9503 & 0.2766 & 0.3584 \\
\hline S12 & 20 & 0.75 & 5 & 0.4116 & 0.4038 & 7.7105 & 7.8767 & 0.4116 & 0.4218 \\
\hline S13 & 20 & 1.5 & 1 & 0.333 & 0.3904 & 9.5511 & 8.1698 & 0.3330 & 0.3966 \\
\hline S14 & 20 & 1.5 & 3 & 0.3016 & 0.3654 & 10.411 & 8.7446 & 0.3016 & 0.3598 \\
\hline S15 & 20 & 1.5 & 5 & 0.3766 & 0.4214 & 8.4824 & 7.5071 & 0.3754 & 0.4241 \\
\hline S16 & 20 & 2.25 & 1 & 0.358 & 0.4624 & 8.9223 & 6.6996 & 0.3571 & 0.4506 \\
\hline S17 & 20 & 2.25 & 3 & 0.3794 & 0.4915 & 8.4181 & 6.1695 & 0.3794 & 0.4972 \\
\hline S18 & 20 & 2.25 & 5 & 0.487 & 0.5125 & 6.2494 & 5.8061 & 0.5958 & 0.5306 \\
\hline S19 & 30 & 0.75 & 1 & 0.4023 & 0.4558 & 7.909 & 6.8245 & 0.4023 & 0.4329 \\
\hline S20 & 30 & 0.75 & 3 & 0.392 & 0.4262 & 8.1343 & 7.4077 & 0.3920 & 0.4222 \\
\hline S21 & 30 & 0.75 & 5 & 0.4327 & 0.5588 & 7.2763 & 5.0549 & 0.4327 & 0.5577 \\
\hline S22 & 30 & 1.5 & 1 & 0.4073 & 0.4351 & 7.8017 & 7.2282 & 0.4073 & 0.4191 \\
\hline S23 & 30 & 1.5 & 3 & 0.391 & 0.4195 & 8.1565 & 7.5454 & 0.3910 & 0.4247 \\
\hline S24 & 30 & 1.5 & 5 & 0.438 & 0.53 & 7.1705 & 5.5145 & 0.4380 & 0.5422 \\
\hline S25 & 30 & 2.25 & 1 & 0.4137 & 0.632 & 7.6663 & 3.9857 & 0.4137 & 0.6619 \\
\hline S26 & 30 & 2.25 & 3 & 0.396 & 0.6141 & 8.0461 & 4.2352 & 0.3960 & 0.5539 \\
\hline S27 & 30 & 2.25 & 5 & 0.4502 & 0.6545 & 6.9319 & 3.6818 & 0.4502 & 0.6542 \\
\hline
\end{tabular}

TABLE 4: Signal-to-noise ratio for wear rate-smaller is better.

\begin{tabular}{lccc}
\hline Level & Load $(\mathrm{N})$ & Velocity $(\mathrm{m} / \mathrm{s})$ & Nanographite wt\% \\
\hline 1 & 8.544 & 8.962 & 8.899 \\
2 & 8.975 & 8.439 & 8.880 \\
3 & 7.677 & 7.794 & 7.417 \\
Delta & 1.298 & 1.168 & 1.482 \\
Rank & 2 & 3 & 1 \\
\hline
\end{tabular}

TABLE 5: Signal-to-noise ratio for coefficient of friction-smaller is better.

\begin{tabular}{lccc}
\hline Level & Load $(\mathrm{N})$ & Velocity $(\mathrm{m} / \mathrm{s})$ & Nanographite wt\% \\
\hline 1 & 6.974 & 8.029 & 6.740 \\
2 & 7.741 & 7.349 & 7.654 \\
3 & 5.720 & 5.057 & 6.040 \\
Delta & 2.021 & 2.972 & 1.614 \\
Rank & 2 & 1 & 3 \\
\hline
\end{tabular}

suggest that the interactions of the experimental factors pose a statistically significant impact on the performance measures examined. Tables 6 and 7 illustrate both the percentage influence of individual factors and the role they play in shaping the overall outcome.

The values were also converted to the $\mathrm{S} / \mathrm{N}$ ratio to determine the quality of characteristics. Also, the $\mathrm{S} / \mathrm{N}$ ratio was established after determining the process' control factors' role on the friction and wear rate coefficient. From Tables 4 and 5, nanographite addition forms the main parameter influencing the wear rate. Those that follow include normal load and sliding speed. Similarly, nanographite addition is the main factor influencing the coefficient of friction, but sliding speed and normal load follow, respectively. The last two parameters are different from the case of the wear rate in which normal load precedes sliding speed. Hence, Tables 6 and 7 illustrate the ANOVA results relative to the composites tested, giving an insight into the friction and wear rate coefficient.

The analysis in Tables 6 and 7 shows the nanographite addition, which translates into the load and poses the 
TABLE 6: Analysis of variance for the signal to noise for wear rate.

\begin{tabular}{|c|c|c|c|c|c|c|c|}
\hline Source & DF & Seq SS & Adj SS & Adj MS & $F$ value & $P$ value & Contribution \\
\hline Load $(\mathrm{N})$ & 2 & 0.013342 & 0.013342 & 0.006671 & 15.90 & 0.002 & $19.23 \%$ \\
\hline Velocity $(\mathrm{m} / \mathrm{s})$ & 2 & 0.011273 & 0.011273 & 0.005637 & 13.43 & 0.003 & $16.25 \%$ \\
\hline Nanographite wt\% & 2 & 0.025750 & 0.025750 & 0.012875 & 30.69 & 0.001 & $37.11 \%$ \\
\hline Load $(\mathrm{N}) * \operatorname{velocity}(\mathrm{m} / \mathrm{s})$ & 4 & 0.007357 & 0.007357 & 0.001839 & 4.38 & 0.036 & $10.60 \%$ \\
\hline $\operatorname{Load}(\mathrm{N}) * \mathrm{Gr} w t \%$ & 4 & 0.006542 & 0.006542 & 0.001635 & 3.90 & 0.048 & $9.43 \%$ \\
\hline Velocity $(\mathrm{m} / \mathrm{s}) *$ Gr wt $\%$ & 4 & 0.001762 & 0.001762 & 0.000441 & 1.05 & 0.440 & $2.54 \%$ \\
\hline Residual error & 8 & 0.003356 & 0.003356 & 0.000420 & & & $4.84 \%$ \\
\hline Total & 26 & 0.069383 & & & & & $100.00 \%$ \\
\hline
\end{tabular}

TABLe 7: Analysis of variance for signal to noise for coefficient of friction.

\begin{tabular}{lccccccc}
\hline Source & DF & Seq SS & Adj SS & Adj MS & $F$ value & $P$ value & Contribution \\
\hline$A$ & 2 & 0.055604 & 0.055604 & 0.027802 & 19.31 & 0.001 & $21.32 \%$ \\
$B$ & 2 & 0.128709 & 0.128709 & 0.064354 & 44.71 & 0.001 & $49.34 \%$ \\
$C$ & 2 & 0.031144 & 0.031144 & 0.015572 & 10.82 & 0.005 & $11.94 \%$ \\
$A * B$ & 4 & 0.011470 & 0.011470 & 0.002867 & 1.99 & 0.189 & 0.095 \\
$A * C$ & 4 & 0.016552 & 0.016552 & 0.004138 & 2.87 & 0.454 & $6.35 \%$ \\
$B * C$ & 4 & 0.005852 & 0.005852 & 0.001463 & 1.02 & & \\
Residual error & 8 & 0.011516 & 0.011516 & 0.001439 & & & \\
Total & 26 & 0.260846 & & & & & $100.00 \%$ \\
\hline
\end{tabular}

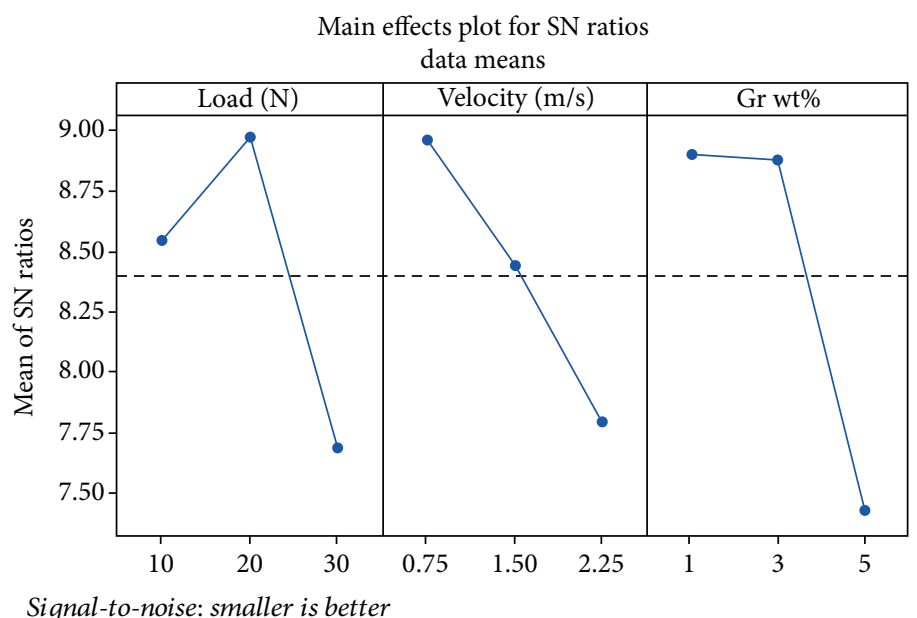

FIGURE 4: S/N plot for wear rate.

greatest impact on the wear rate $(F=44.71)$. The other two factors affect the wear rate in terms of load $(F=19.31)$ and sliding speed or velocity $(F=10.82)$. The implication is that the need to pay more attention to this factor cannot be overemphasized.

3.2. Focusing on the Impact of the Test Parameters on the Coefficient of Friction and Wear Rate. Figures 4 and 5 illustrate the impact of different parameters on the coefficient of friction and wear rate. In situations where a given parameter's line was closer to horizontal, it was inferred that it did not exhibit a significant impact. On the other hand, in situations where lines for certain parameters showed the highest degree of inclination, it was inferred that the effect was the most significant. Indeed, nanographite addition depicted the strongest impact on the rate of wear. Therefore, it was established that an increase in normal load tends to increase the wear rate. However, nanographite addition accompanied 


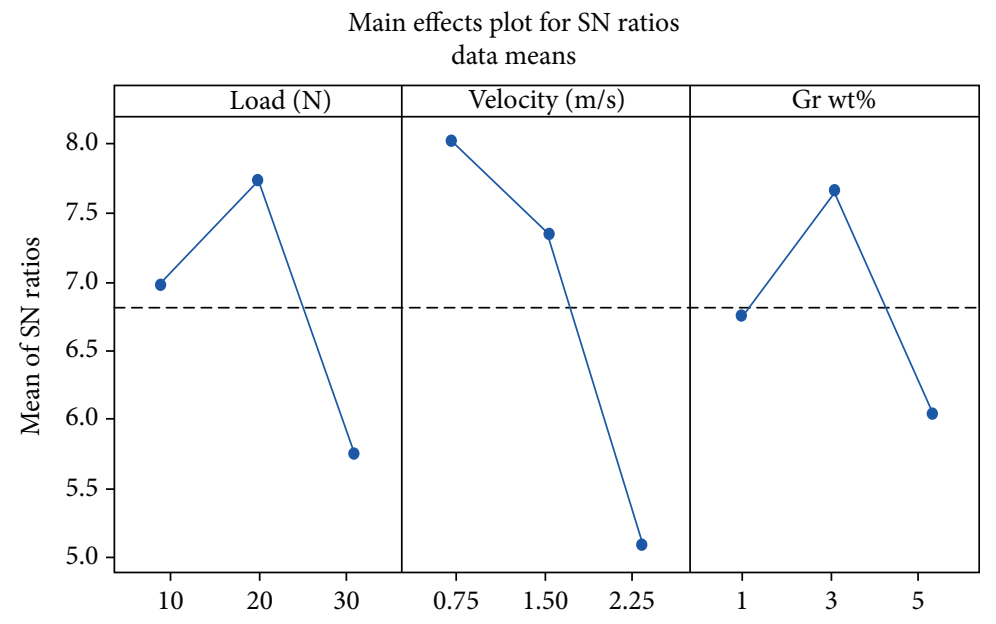

Signal-to-noise: smaller is better

FIgURe 5: S/N plot for COF.

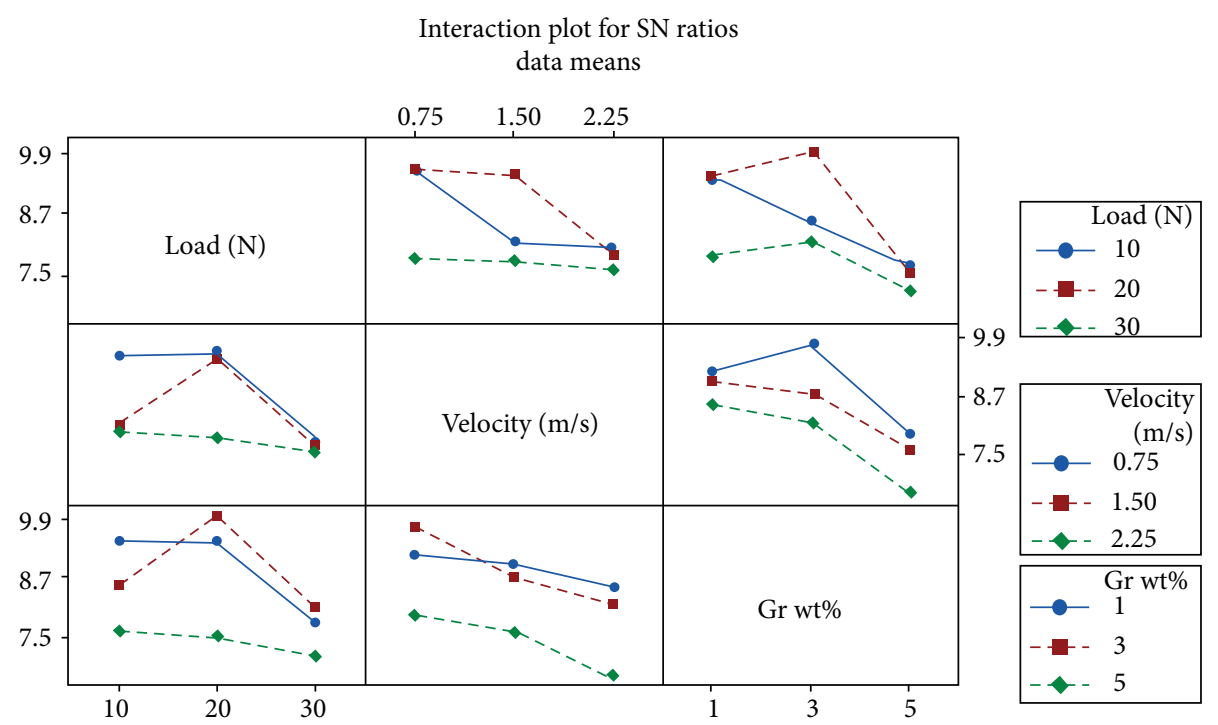

Signal-to-noise: smaller is better

Figure 6: Interaction plot for $\mathrm{S} / \mathrm{N}$ ratio wear rate.

by increased sliding speed depicted a decrease in wear rate. At the highest sliding speed, nanographite addition, and the lowest normal load, the wear rate was the lowest.

From Figures 4 and 5, it was also evident that for the curve of nanographite addition, the largest slope was the most significant factor affecting the coefficient of friction. With a decrease in sliding speed and nanographite addition, the coefficient of friction was found to decrease. As the normal load increased, the coefficient of friction also increased. The interactions between the analyzed parameters and their impact on the friction and wear rate coefficient are illustrated in Figures 6 and 7.

3.3. Multiple Linear Regressions. MINITAB 18 software was used to establish a multiple linear regression model with the experiment's linear dependence occurring between values of nanographite addition, sliding speed, and normal load. ANOVA analysis led to the establishment of the linear regression equation, setting the nanographite addition, sliding speed, and normal load values:

$$
\begin{aligned}
\text { Wear rate }= & 0.1807+0.00641 A+0.0539 B+0.0201 C \\
& -0.00187 A B+0.00559 B C-0.000590 C A .
\end{aligned}
$$

For the coefficient of friction (COF), the regression equation was

$$
\begin{aligned}
\mathrm{COF}= & 0.232+0.00243 A+0.1359 B-0.0122 C \\
& -0.00156 A B+0.0007 B C+0.00104 C A .
\end{aligned}
$$




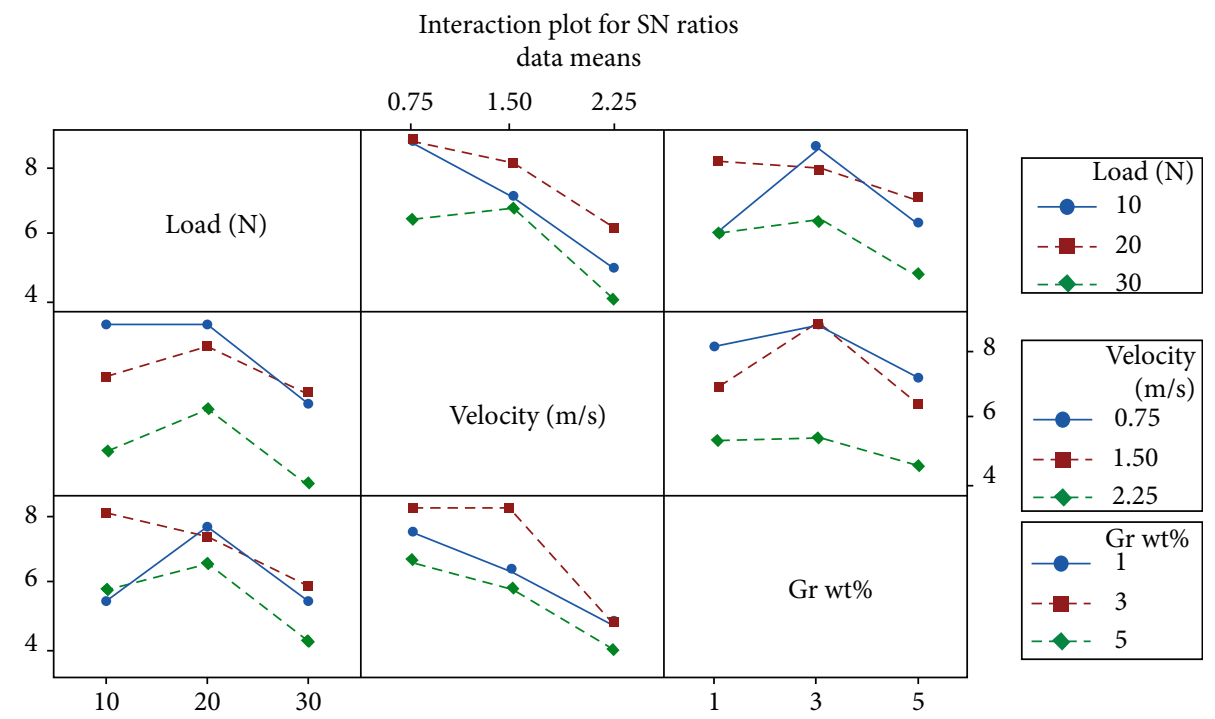

Signal-to-noise: smaller is better

FIgURE 7: Interaction plot for $\mathrm{S} / \mathrm{N}$ ratio COF.

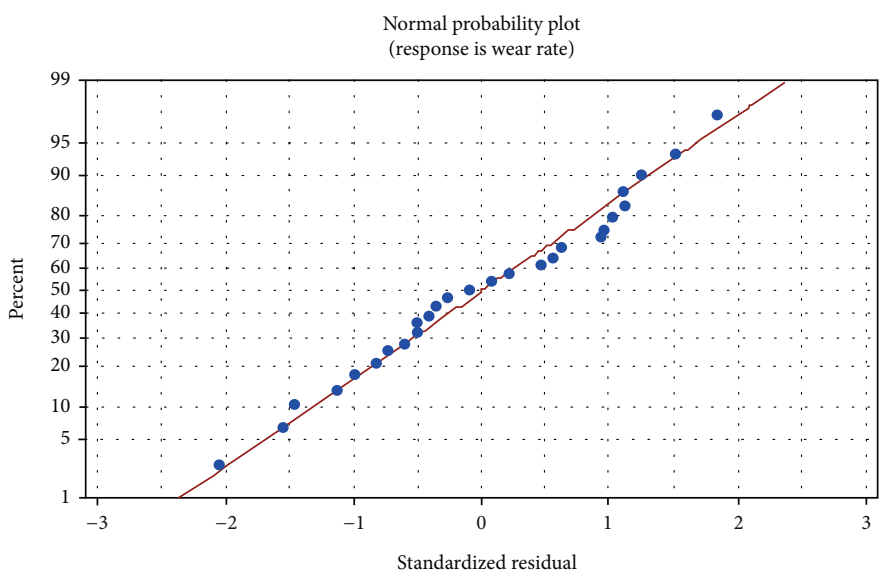

FIgURE 8: Normal probability plots of residuals for wear rate.

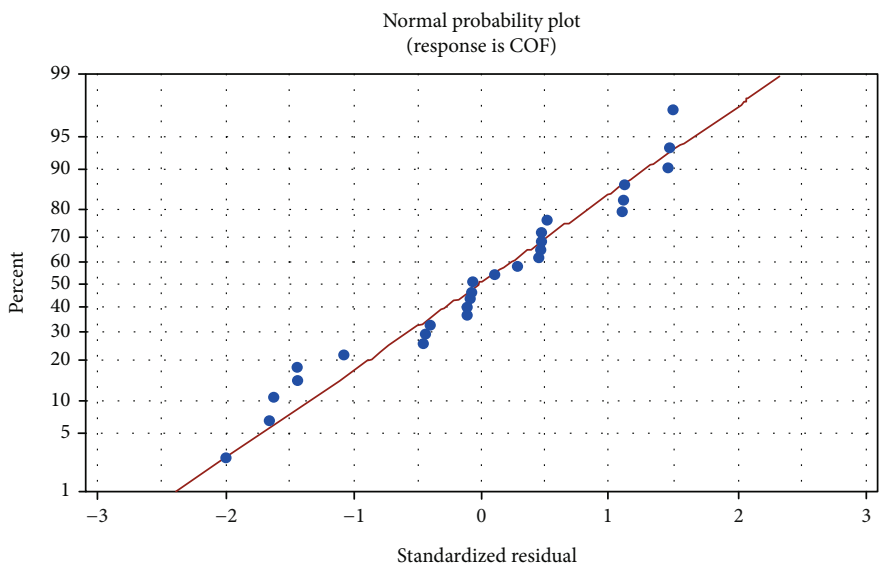

FIGURE 9: Normal probability plots of residuals for COF. 

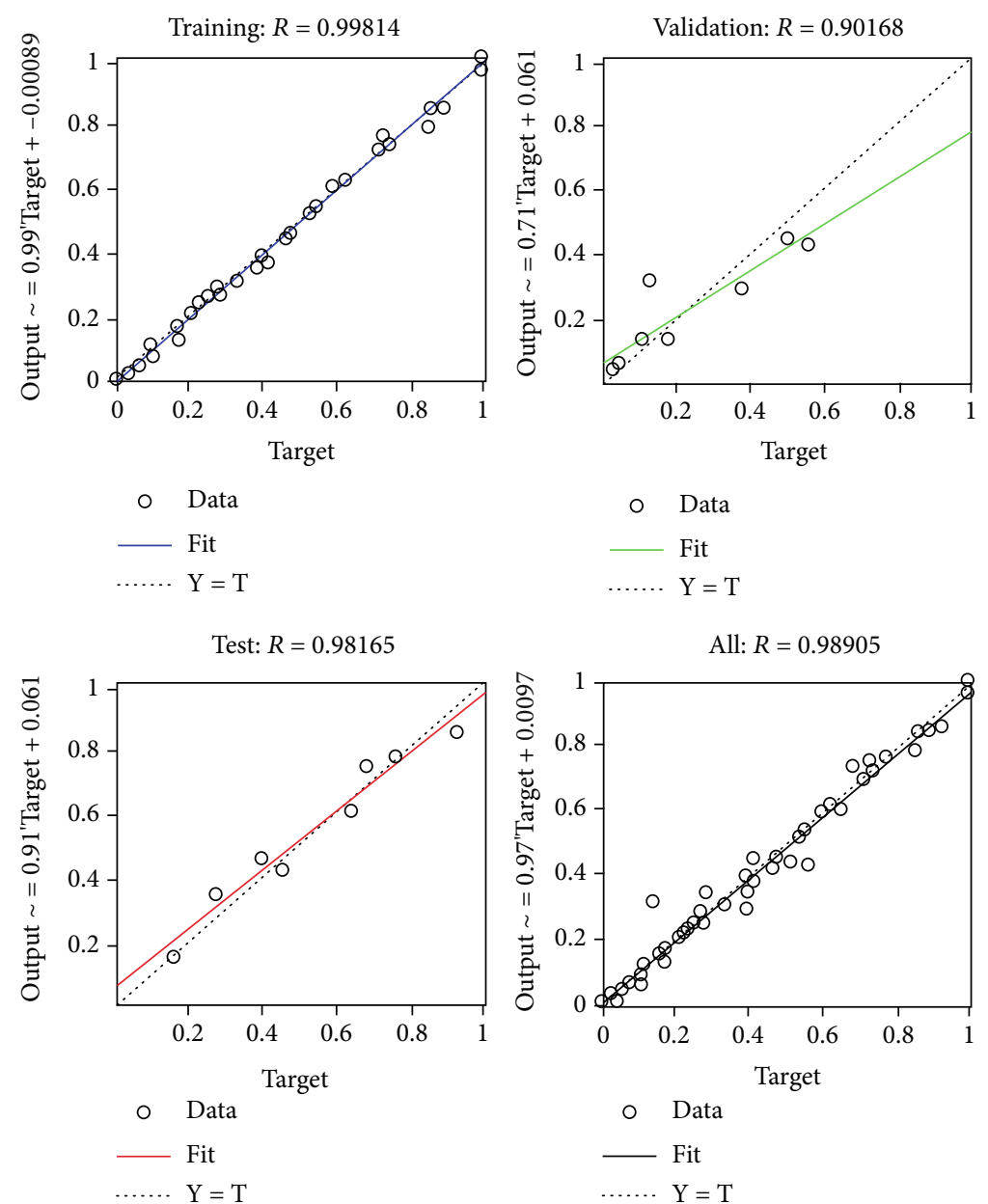

Best validation performance is 0.0078254 at epoch 1

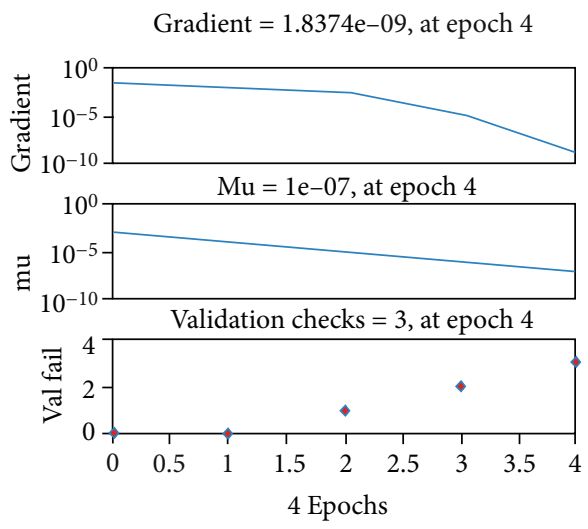

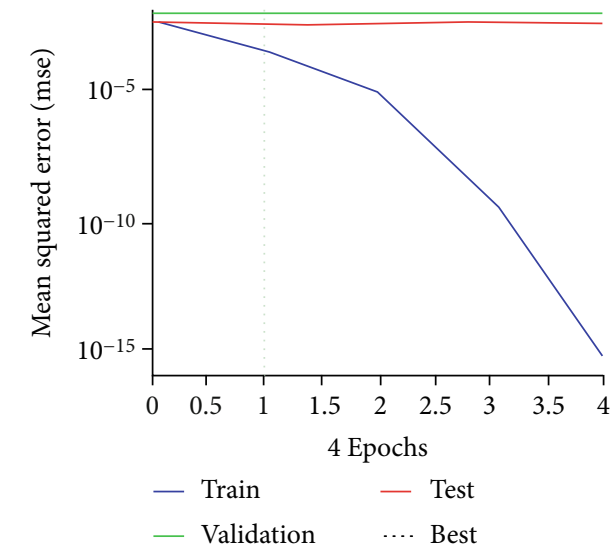

(a)

(b)

FIgURE 10: ANN mean square error and training state plot.

From the coefficients obtained in equations (2) and (3) above, the study established that when each factor was considered individually, the impact posed on the coefficient of friction and wear rate of the composites under examination differed. As the normal load increased, the coefficient of fric- tion and wear rate increased. However, the friction and wear rate coefficient decreased with an increase in nanographite content and sliding speed. The eventuality is that the models developed to predict the coefficient of friction and wear rate relative to the composites that were tested proved adequate, 
as shown in equations (2) and (3), with the points in Figures 8 and 9 confirming this result because they lie closer to the estimated line perceived to exhibit small disintegration.

3.4. Experimental Confirmation. Focus on the eventual impact of the control parameters examined. In this case, the role of experimental confirmation is to verify the results accruing from the Taguchi method. The experimental confirmation is also used to ensure that the quality characteristics are tested. Also, the optimal impact factor levels are used to establish values of the optimal friction coefficient and wear rate. Total error losses are considered to estimate the optimal levels. ANN mean square error and training state plot are shown in Figure 10.

Equation (4) was used to predict the optimal rate of wear rate and considered individual effects of nanographite $(R)$, sliding speed $(S)$, and load $(L)$. The equation was

$$
\mathrm{Wr}=T_{w}+\left(L 1-T_{W}\right)+\left(S 3-T_{W}\right)+\left(R 3-T_{W}\right) .
$$

Levels of the factors under examination were used to predict the optimal coefficient of friction. With personal effects of the respective factors governing the predicted optimal friction coefficient development, equation (5) was used:

$$
\mu=T_{\mu}+\left(L 1-T_{\mu}\right)+\left(S 3-T_{\mu}\right)+\left(R 3-T_{\mu}\right) .
$$

3.5. The Case of Artificial Neural Network (ANN). In this experiment, ANN training and testing were achieved via MATLAB R2016a. From the results, this study established that a reasonably good performance arises from the trained ANN. The inference was informed by the similarity between the test and validation curves. It is also worth highlighting that the ANN training would extend to the $4^{\text {th }}$ epoch, but epoch 1 formed the point associated with optimal or the best validation performance. At this point (epoch 1), a value of 0.0078254 was obtained.

On the other hand, a value of $1.8374 \times 10^{-9}$ was obtained for the case of epoch 4, illustrating a value closer to zero. Another notable trend was that as the number of epochs increased, the gradient value decreased. Table 8 summarizes the results of the confirmation experiments for the wear rate and coefficient of friction.

The regression equation was obtained upon employing the ANN output of training and ANOVA analysis before comparing the findings with experimental data. Figure 11 shows the findings after comparing the study's coefficient of friction and wear rate with the experimental data. Indeed, the analysis of the data obtained revealed that the two methods are highly reliable. Particularly, there was a close similarity between the findings established by ANN training and the experimental data. As such, the ANN was highly efficient relative to the prediction of the coefficient of friction and wear rate.

3.6. Analysis of the Worn Surface. Energy-dispersive spectroscopy (EDS) and scanning electron microscopy aided in testing and analyzing the tested composites' worn surfaces.
TABLE 8: Results of the confirmation experiments for wear rate and coefficient of friction.

\begin{tabular}{lccc}
\hline & Prediction & Experimental & ANN \\
\hline Wear rate $10^{-5}\left(\mathrm{~mm}^{3} / \mathrm{m}\right)$ & 0.118 & 0.195 & 0.125 \\
$L 1, S 3, R 3$ & 18.56 & 17.12 & 17.56 \\
S/N ratio $(\mathrm{db})$ & 0.062 & 0.058 & 0.060 \\
Coefficient of friction & 24.15 & 24.731 & 24.315 \\
$L 1, S 3, R 3$ & & & \\
S/N ratio $(\mathrm{db})$ & &
\end{tabular}

In most of the composites, the main mechanism of wear was similar. This dominant mechanism involves combinations of light abrasion and wiping or light adhesion identified in Figures 12(a)-12(d). Also, the backscattered electron image (BEC) aided in illustrating the morphology of the alloy, while the secondary electron image (SEI) aided in presenting the worn surface. Imperative to highlight is that the EDS analysis revealed the presence of nanographite particles.

Over the worn surface, the particles were randomly distributed. Hence, they were avowed to account for relatively high values of the coefficient of friction. It was also observed that silicon carbide is more brittle compared to the rest of the composite matrix. The EDS analysis also confirmed that all composite contact surfaces experienced counterbody material transfer. Notably, the majorities of counterbody materials transferred were in front of and around the nanographite particles (Figure 12(b)).

Figure 13 shows the worn surface of hybrid composite (sample S11) SEM with corresponding EDS analysis results. From the observations about the EDS analysis that focused on transferred material, it was established that counterbody material, oxides, and nanographite constituted the mixture in the transferred material, reflecting a mechanically mixed layer similar to that which is mostly observed in AMCs that have been examined under experimental settings with dry sliding conditions [22]. In the AMCs, the layer exists as a thin lubricant film occurring between the disc surface and the counterpart block. Effects of this layer include reductions in the coefficient of friction, wear, and heat generation because of the friction $[20,21]$. Nanographite has also been found on the worn surfaces of hybrid composites. During the compocasting or composite preparation process, nanographite particles were fragmented to form small and fine particles. As such, they could not be detected in the form of large particles.

\section{Conclusion}

The Taguchi method plays a significant role in analyzing aluminium matrix composites' sliding tribological behaviour. The Taguchi method offers an efficient, systematic, and simple methodology for optimizing wear and friction test parameters. This study established that wt $\%$ addition of nanographite and an increase of sliding speed tend to decrease the coefficient of friction and wear rate of tested 


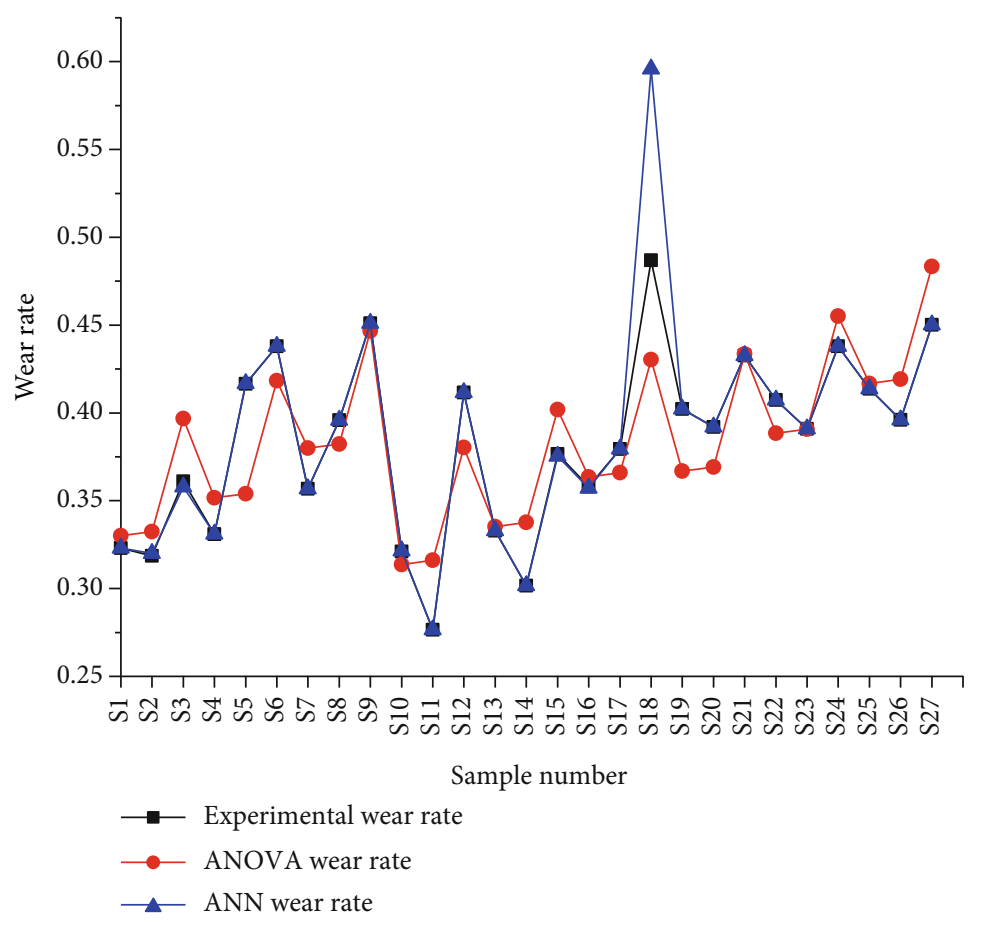

(a)

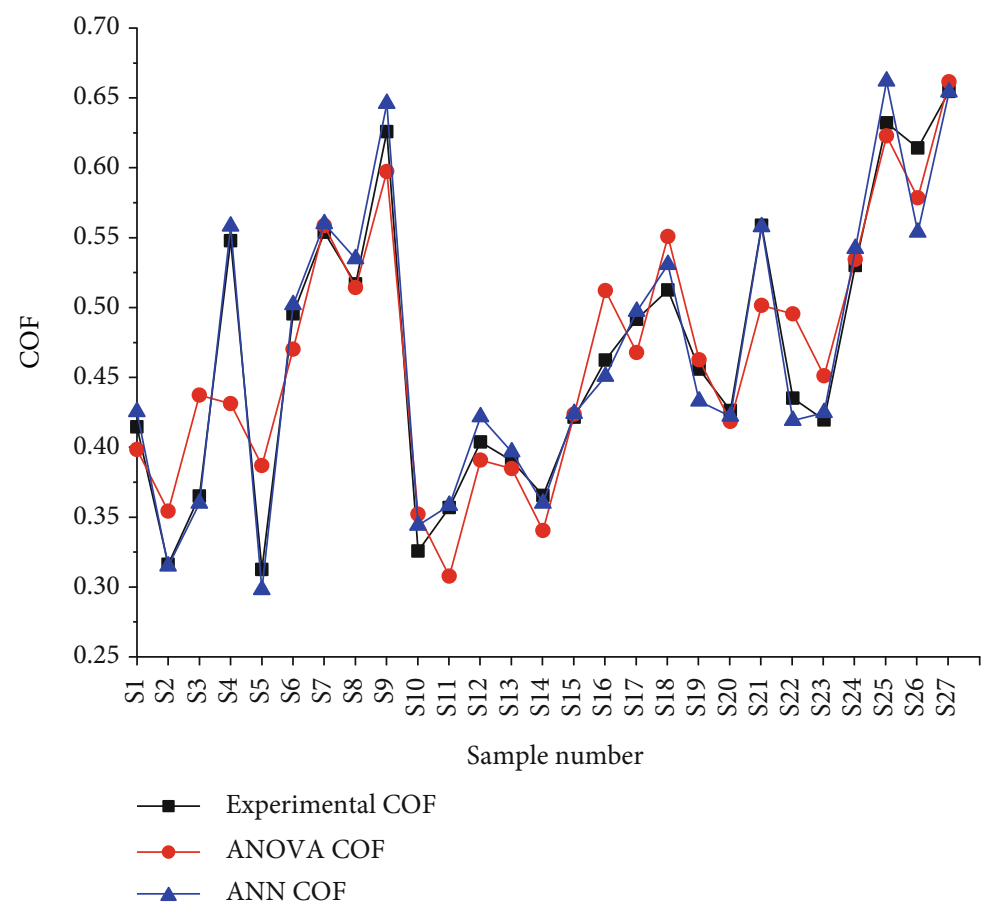

(b)

Figure 11: Comparison of results for (a) wear rate and (b) coefficient of friction.

composite tends. On the other hand, findings suggested that the increase of normal load leads to an increase in friction and wear rate coefficient. In the hybrid composites, minimal friction coefficient and wear rate were observed to be at maximal sliding speed and minimal load for the case of nanographite. The study concluded that sliding speed and normal load factors exhibit the lowest effect on wear rate while wt $\%$ of nanographite exhibits the largest effect. Also, individual parameter interactions revealed a smaller impact (interactions involving wt $\%$ of nanographite and sliding speed, sliding speed and normal load, and wt\% of nanographite and normal load). From the results of MATLAB R2018 


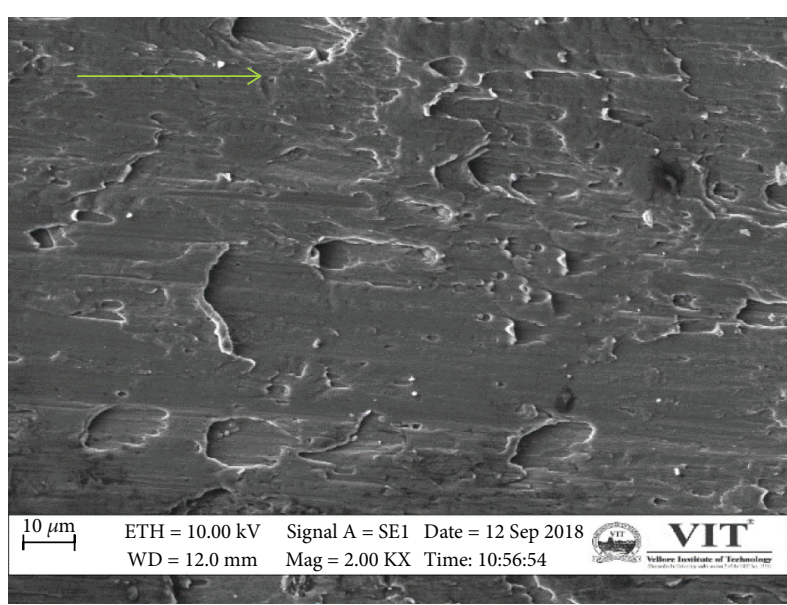

(a) $\mathrm{Al}-\mathrm{Cu}-\mathrm{Mg} /$ nanographite at $\mathrm{S} 7$

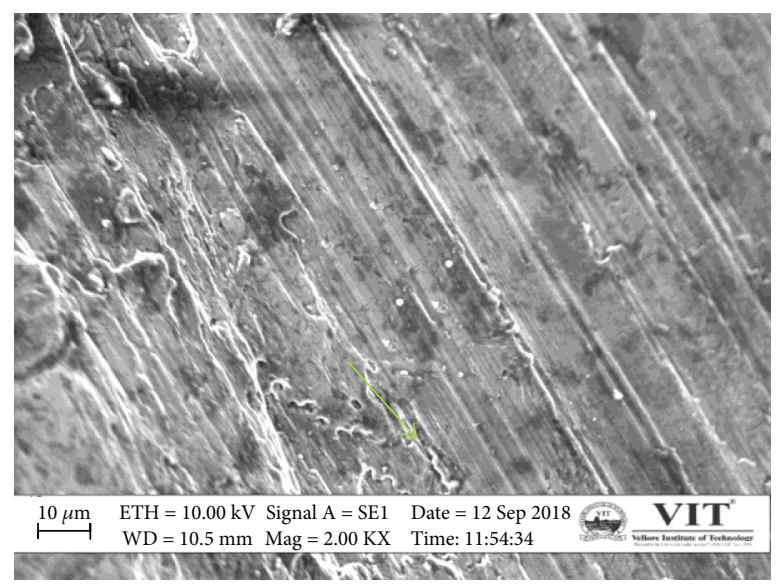

(c) Al-Cu-Mg/nanographite at S11

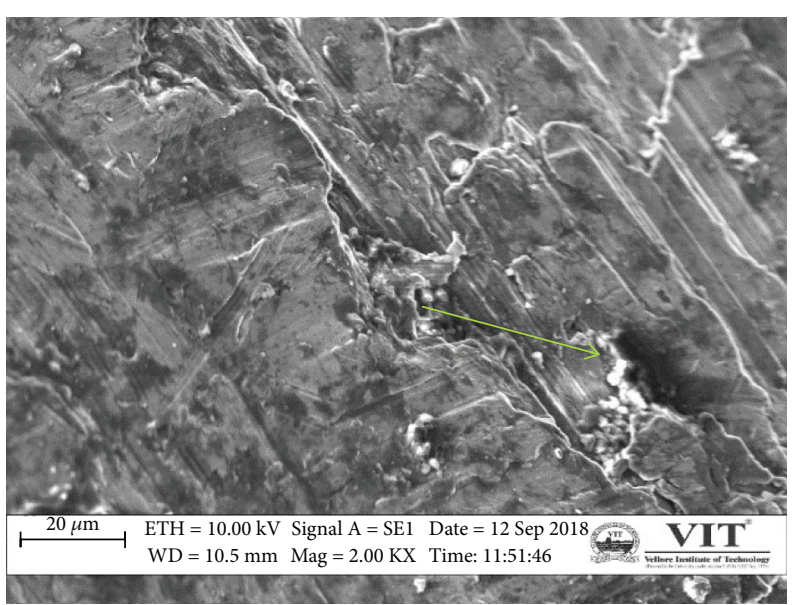

(b) Al-Cu-Mg/nanographite at S12

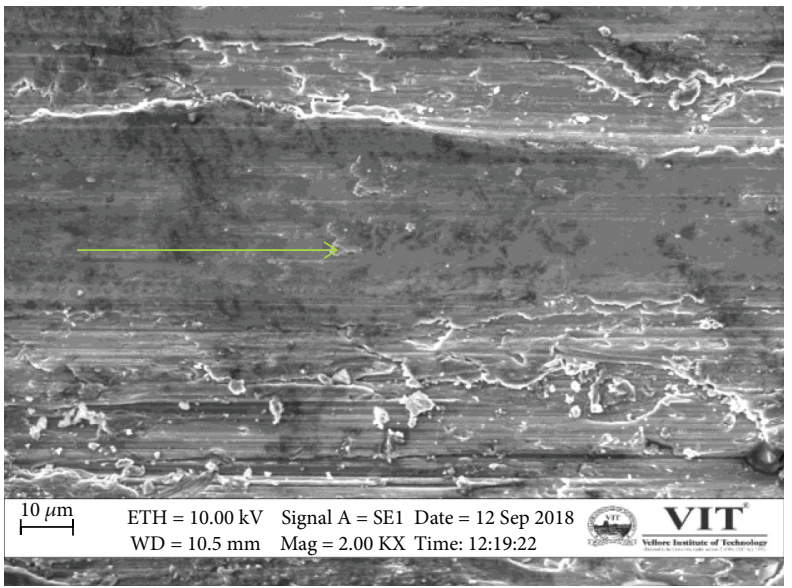

(d) $\mathrm{Al}-\mathrm{Cu}-\mathrm{Mg} /$ nanographite at $\mathrm{S} 19$

FIGURE 12: Worn surface of hybrid composite.
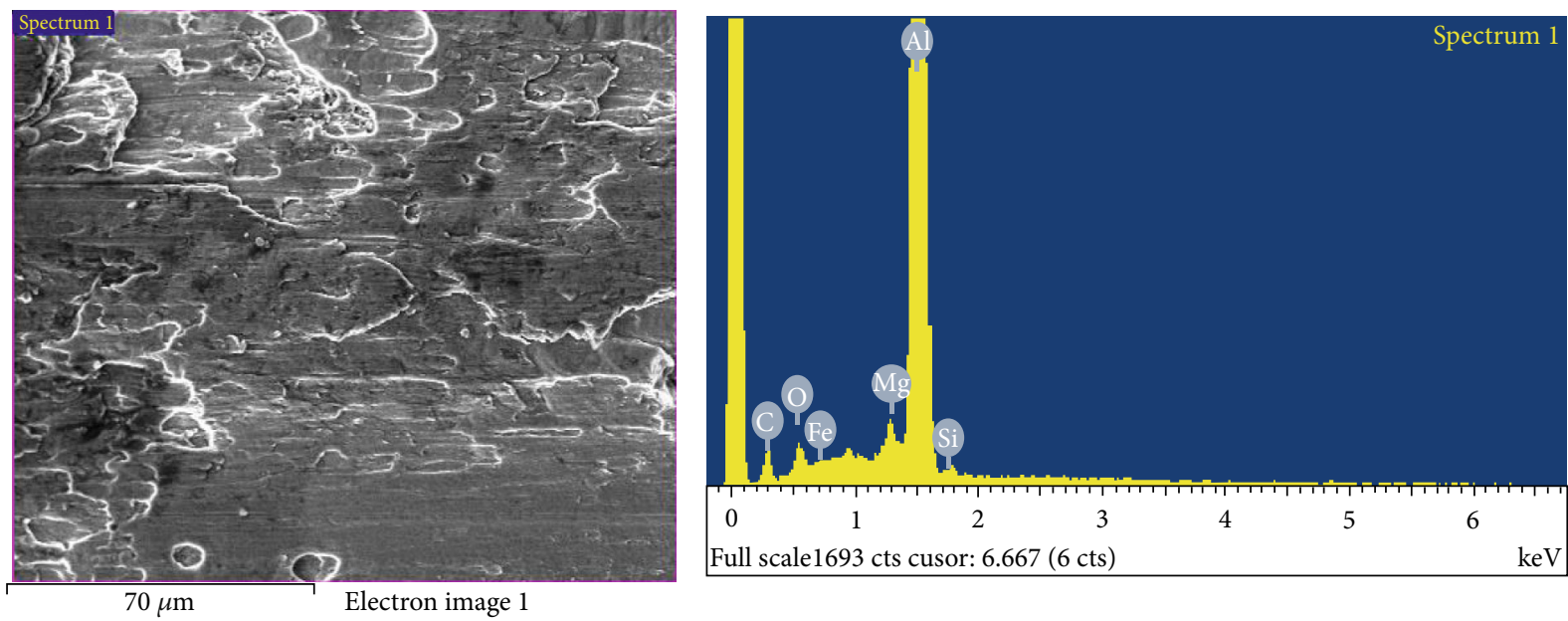

FIGURE 13: Worn surface of hybrid composite (sample S11) SEM and corresponding EDS analysis results. 
software, ANN proved efficient in predicting the coefficient of friction and wear rate because the results obtained by ANN and ANOVA were similar to the experimental data.

\section{Data Availability}

The data used to support the findings of this study are included within the article. Should further data or information be required, these are available from the corresponding author upon request.

\section{Disclosure}

This research and publication was performed as part of the employment at the Kombolcha Institute of Technology, Wollo University, Kombolcha, Amhara, Ethiopia.

\section{Conflicts of Interest}

The authors declare that there are no conflicts of interest regarding the publication of this paper.

\section{Acknowledgments}

The authors thank Saveetha School of Engineering, SIMATS, Chennai, and Vellore Institute of Technology, Chennai, for providing characterization support to complete this research work.

\section{References}

[1] A. K. F. Hassan and S. Mohammed, "Artificial neural network model for estimation of wear and temperature in pin-disc contact," Universal Journal of Mechanical Engineering, vol. 4, no. 2, pp. 39-49, 2016.

[2] A. Vencl, I. Bobic, S. Arostegui, B. Bobic, A. Marinkovic, and M. Babic, "Structural, mechanical and tribological properties of A356 aluminium alloy reinforced with $\mathrm{Al}_{2} \mathrm{O}_{3}, \mathrm{SiC}$ and $\mathrm{SiC}$ + graphite particles," Journal of alloys and compounds, vol. 506, no. 2, pp. 631-639, 2010.

[3] B. Stojanović and J. Glišović, "Automotive engine materials," in Saleem Hashmi (editorin-chief), Reference Module in Materials Science and Materials Engineering, pp. 1-9, Elsevier, Oxford, 2016.

[4] L. Natrayan and M. Senthil Kumar, "An integrated artificial neural network and Taguchi approach to optimize the squeeze cast process parameters of $\mathrm{AA} 6061 / \mathrm{Al}_{2} \mathrm{O}_{3} / \mathrm{SiC} / \mathrm{Gr}$ hybrid composites prepared by novel encapsulation feeding technique," Materials Today Communications, vol. 25, article 101586, 2020.

[5] R. Ambigai and S. Prabhu, "Optimization of friction and wear behaviour of Al- $\mathrm{Si}_{3} \mathrm{~N}_{4}$ nano composite and Al-Gr- $\mathrm{Si}_{3} \mathrm{~N}_{4}$ hybrid composite under dry sliding conditions," Transactions of Nonferrous Metals Society of China, vol. 27, no. 5, pp. 986997, 2017.

[6] B. Stojanović, M. Babić, S. Mitrović, A. Vencl, N. Miloradović, and M. Pantić, "Tribological characteristics of aluminium hybrid composites reinforced with silicon carbide and graphite. A review," Journal of the Balkan Tribological Association, vol. 19 , no. 1 , p. $83,2013$.
[7] A. K. Mondal and S. Kumar, "Dry sliding wear behaviour of magnesium alloy based hybrid composites in the longitudinal direction," Wear, vol. 267, no. 1-4, pp. 458-466, 2009.

[8] A. Kumar and M. Kumar, "Mechanical and dry sliding wear behaviour of $\mathrm{B} 4 \mathrm{C}$ and rice husk ash reinfroced $\mathrm{Al} 7075$ alloy hybrid composite for armors application by using Taguchi techniques," Materials Today: Proceedings, vol. 27, pp. 26172625, 2020.

[9] D. B. Miracle, "Metal matrix composites - From science to technological significance," Composites science and technology, vol. 65, no. 15-16, pp. 2526-2540, 2005.

[10] D. C. Montgomery, Design and Analysis of Experiments, John Wiley \& Sons, 2012.

[11] A. Çiçek, T. Kivak, and G. Samtaş, "Application of Taguchi method for surface roughness and roundness error in drilling of AISI 316 stainless steel," Strojniški vestnik-Journal of Mechanical Engineering, vol. 58, no. 3, p. 165, 2012.

[12] K. R. Roy, A Primer on the Taguchi Method, Van Nostrand Reinhold, New York, 1990.

[13] Y. Sahin, "The prediction of wear resistance model for the metal matrix composites," Wear, vol. 258, no. 11-12, p. 1717, 2005.

[14] M. Babic, A. Vencl, S. Mitrović, and I. Bobić, "Influence of T4 heat treatment on tribological Behavior of Za27 alloy under lubricated sliding condition," Tribology Letters, vol. 36, no. 2, pp. 125-134, 2009.

[15] M. Babić, B. Stojanović, S. Mitrović et al., "Wear properties of A356/10SiC/1Gr hybrid composites in lubricated sliding conditions," Tribology in industry, vol. 35, no. 2, p. 148, 2013.

[16] M. L. Ted Guo and C. Y. A. Tsao, "Tribological behavior of self-lubricating aluminium/SiC/graphite hybrid composites synthesized by the semi-solid powder-densification method," Composites science and technology, vol. 60, no. 1, pp. 65-74, 2000.

[17] M. Sarikaya, H. Dilipak, and A. Gezginet, "Optimization of the process parameters for surface roughness," Mat tehnol, vol. 49, no. 1, p. 139, 2015.

[18] N. Chawla and K. K. Chawla, "Metal-matrix composites in ground transportation," JoM, vol. 58, no. 11, p. 67, 2006.

[19] S. Basavarajappa and G. Chandramohan, "Wear studies on metal matrix compositeTaguchi approach," Journal of Materials Science and Technology, vol. 21, no. 6, p. 845, 2005.

[20] S. Suresha and B. K. Sridhara, "Effect of silicon carbide particulates on wear resistance of graphitic aluminium matrix composites," Materials \& Design, vol. 31, no. 9, pp. 4470-4477, 2010.

[21] A. Vencl, F. Vučetić, B. Bobić, J. Pitel, and I. Bobić, “Tribological characterisation in dry sliding conditions of compocasted hybrid A356/SiCp/Grp composites with graphite macroparticles," The International Journal of Advanced Manufacturing Technology, vol. 100, no. 9-12, pp. 2135-2146, 2019.

[22] S. V. Prasad and R. Asthana, "Aluminum Metal-Matrix Composites for Automotive Applications: Tribological Considerations," Tribology letters, vol. 17, no. 3, pp. 445-453, 2004.

[23] T. Kivak, "Optimization of surface roughness and flank wear using the Taguchi method in milling of Hadfield steel with PVD and CVD coated inserts," Measurement, vol. 50, pp. 19-28, 2014.

[24] U. Soy, F. Ficici, and A. Demir, "Evaluation of the Taguchi method for wear behavior of Al/Sic/B4c composites," Journal of Composite Materials, vol. 46, no. 7, pp. 851-859, 2012. 
[25] Y. Kayali, B. Gokce, E. Mertgenc, F. Colak, and R. Kara, "Analysis of wear behavior of borided AISI 52100 steel with the Taguchi method," The Journal of the Balkan Tribological Assosiation, vol. 19, no. 3, p. 365, 2013.

[26] M. O. Bodunrin, K. K. Alaneme, and L. H. Chown, "Aluminium matrix hybrid composites: a review of reinforcement philosophies; mechanical, corrosion and tribological characteristics," Journal of Materials Research and Technology, vol. 4, no. 4, pp. 434-445, 2015.

[27] B. Stojanović and S. Milojević, "Characterization, manufacturing and application of metal matrix composites," in Advances in Materials Science Research, M. C. Wythers, Ed., vol. 30, pp. 83-113, Nova Science Publishers, New York, 2017. 